\title{
Vaccine development to control the rising scourge of antibiotic-resistant Acinetobacter baumannii: a systematic review
}

\author{
Ravinder Singh ${ }^{1} \cdot$ Neena Capalash $^{2} \cdot$ Prince Sharma $^{3}$ (])
}

Received: 5 October 2021 / Accepted: 11 February 2022 / Published online: 2 March 2022

(c) King Abdulaziz City for Science and Technology 2022

\begin{abstract}
Acinetobacter baumannii has emerged as one of major nosocomial pathogen and global emergence of multidrug-resistant strains has become a challenge for developing effective treatment options. A. baumannii has developed resistance to almost all the antibiotics viz. beta-lactams, carbapenems, tigecycline and now colistin, a last resort of antibiotics. The world is on the cusp of post antibiotic era and the evolution of multi-, extreme- and pan-drug-resistant A. baumannii strains is its obvious harbinger. Various combinations of antibiotics have been investigated but no successful treatment option is available. All these failed efforts have led researchers to develop and implement prophylactic vaccination for the prevention of infections caused by this pathogen. In this review, the advantages and disadvantages of active and passive immunization, the types of sub-unit and multi-component vaccine candidates investigated against $A$. baumannii viz. whole cell organism, outer membrane vesicles, outer membrane complexes, conjugate vaccines and sub-unit vaccines have been discussed. In addition, the benefits of Reverse vaccinology are emphasized here in which the potential vaccine candidates are predicted using bioinformatic online tools prior to in vivo validations.
\end{abstract}

Keywords Acinetobacter baumannii $\cdot$ Multidrug resistance $\cdot$ Vaccine $\cdot$ Reverse vaccinology $\cdot$ Epitopes

\section{Introduction}

Acinetobacter baumannii (A. baumannii) is associated with a number of nosocomial infections, such as pneumonia, bloodstream infections, meningitis, skin and urinary tract infections in hospitals and intensive care units(Peleg et al. 2008; Moubareck and Halat 2020). Multidrug resistance (Abdi et al. 2020; López-Durán et al. 2020), biofilm formation ability (Espinal et al. 2012; Yang et al. 2012) and desiccation tolerance (Espinal et al. 2012; Wang et al. 2020) are the foremost characteristics making it a critical priority pathogen. Patients requiring mechanical ventilation in hospitals are major targets of A. baumannii causing ventilator-associated pneumonia (VAP) (Brotfain et al. 2017; Čiginskienè et al. 2019). It

Prince Sharma

princess@pu.ac.in

1 Department of Experimental Medicine and Biotechnology, PGIMER, Sector 12, Chandigarh 160012, India

2 Department of Biotechnology, Panjab University, BMS Block I, Sector 25, Chandigarh- 160014, India

3 Department of Microbiology, Panjab University, BMS Block I, Sector 25, Chandigarh- 160014, India is a common pathogen found in patients of burn injuries and military personnel injured in war. In these critical conditions, vaccination may emerge as solution and it can prevent the initial bacterial invasion to avoid the massive colonization of bacteria which causes infection. Vaccine development against A. baumannii infections is being explored extensively and multiple potential vaccine candidates have been identified (Garg et al. 2016; Singh et al. 2016b, 2017; Fereshteh et al. 2020). Patients who tend to be admitted in hospital intensive care units (ICUs) may be vaccinated with enough time to allow for the generation of an immune response to make them ready for exposure to A. baumannii. Method of immunization could be selected by analyzing the potential targets of $A$. baumannii. For example, patients admitted in the hospitals for longer duration can be actively immunized and they will get enough time to develop immunity against $A$. baumannii. On the other hand, passive immunization may serve the patients for whom the risk of infection is not foreseen, such as in traumatic injuries, severe burn injuries or in emergent surgery. Although passive immunization is therapeutic and has the potential to provide instantaneous protective immunity, active immunization is safe and cost effective against bacterial infections. 
Future treatment of $A$. baumannii infections may be through an effective vaccine that augments host responses and results in limiting the bacterial infections. Preparing the host for invading nosocomial pathogens appears to be most promising treatment option as adaptive immune response (Antigen presenting cells, B cells and T cells) leads to protection through cellular or humoral immunity. Vaccination with modified or inactivated pathogens or components derived from these pathogens stimulates adaptive immune response in an antigen-specific manner.

\section{Prevalence of $A$. baumannii in global and Indian context}

A. baumannii has established itself as one of the most prominent nosocomial pathogens in hospitals and its antimicrobial-resistant clinical strains have been documented at alarming rate worldwide (Holt et al. 2016; Meumann et al. 2019; Brink 2019; Pormohammad et al. 2020). In certain European, South American and Asian hospitals, $A$. baumannii has shown extensive drug resistance pattern as compared to clinical strains isolated from the patients in ICUs in the Nordic countries, the Netherlands and The USA (Falagas and Karveli 2007). Pormohammad et al. (2020) have reported the global prevalence of colistin resistance at increased rate in South-East Asia and East Mediterranean than any other region in world. The highest and the lowest rates of resistance were observed for cefotaxime (99\%) in Africa and colistin (1.1\%) in Western Pacific. The rate of colistin resistance was highest in Lebanon (17.5\%) followed by China (12\%) and was lowest in Germany (0.2\%). A. baumannii has become highly prominent and has been found all over the regions of India. In 2001, Sengupta et al. reported the incidence of $A$. baumannii in wound infections of burn patients. These infections led to septicemia and in few cases, death. When characterized, these bacteria were found multidrug resistant (Sengupta et al. 2001). The prevalence of metallo- $\beta$-lactamases (MBLs) among A. baumannii clinical isolates obtained from South Indian tertiary care hospitals has been reported and the strains were characterized for their antimicrobial susceptibility (Karthika et al. 2009). Most of the isolates showed resistance to imipenem (100\%), meropenem $(89 \%)$, amikacin $(80 \%)$, cefotaxime $(89 \%)$ and ciprofloxacin (72\%). In addition, prevalence of A. bauman$n i i$ in patients is of great concern. Azim et al. reported $A$. baumannii colonization in 37 out of 96 patients included in the study conducted in Lucknow in India. They found simultaneous colonization of $A$. baumannii and $P$. aeruginosa in 12 patients and all were extended-spectrum $\beta$-lactamase (ESBL)- and metallo- $\beta$-lactamase (MBL)-producing isolates(Azim et al. 2010). Srirangaraj et al (2015) described an antibiotic-resistant $A$. baumannii clinical isolate from a 70-year-old patient who developed urinary tract infection caused due to indwelling urinary catheter, prolonged stay in ICU and exposure to broad spectrum antibiotics. This isolate was found resistant to all the drugs used for urinary tract infections (UTI), such as amikacin, ceftriaxone, co-trimoxazole, nalidixic acid, nitrofurantoin and norfloxacin. Further analysis of this isolate showed resistance to aminoglycosides (gentamycin and tobramycin), fluroquinolones (ciprofloxacin and levofloxacin), piperacillin (tazobactum) and imipenem. This MDR isolate was found sensitive to polymyxin B and colistin only (Srirangaraj et al. 2015). Vijayakumar et al. described the prevalence of carbapenem resistance among the $A$. baumannii isolates from tertiary care hospital in South India. They found blaOXA-51 and blaOXA-23 genes in all the 103 isolates and 94 were carbapenemase producers. blaNDM and blaVIM genes were predominant among metallo- $\beta$-lactamases and $80 \%$ of the isolates had ISAba1 upstream blaOXA-23 gene which suggests that this insertion element acts as a promoter and facilitates its increased expression(Vijayakumar et al. 2016).

Antibiotic monotherapy has shown limited effect on these bacteria hence antibiotic combinations have been tried against them. Muthusamy et al. demonstrated in vitro activities of rifampicin and polymyxins against carbapenemresistant $A$. baumannii in a tertiary care hospital from South India. They screened 20,282 clinical isolates obtained from various specimens, such as tracheal aspirate, broncho-alveolar lavage fluid, blood, endotracheal tube tip, sputum, ascitic fluid and wound swabs. All the isolates were found sensitive to polymyxin B and $80 \%$ were resistant to rifampicin. Only carbapenem-resistant strains were included in further study and $78 \%$ were found sensitive, $12 \%$ intermediate sensitive and $10 \%$ resistant to colistin. The increasing emergence of MDR A. baumannii in all parts of India is alarming and antimicrobial stewardship programs are needed to prevent the emergence and spread of antibiotic resistance (Vijayakumar et al. 2016; Banerjee et al. 2018; Odsbu et al. 2018; Kalal et al. 2020; Nguyen and Joshi 2021).

\section{The need for vaccine against $A$. baumannii}

A. baumannii is an important nosocomial pathogen causing various human infections in critically ill patients (Dijkshoorn et al. 2007) and is highly resistant to many antimicrobials (Peleg et al. 2008; Kempf and Rolain 2012; Abdi et al. 2020). Acquired resistance to broad-spectrum $\beta$-lactams in $A$. baumannii is mainly due to enzymatic degradation by $\beta$-lactamases and resistance to broad-spectrum cephalosporins usually results from overexpression of the chromosomal AmpC-type cephalosporinase (Corvec et al. 2003; Rodríguez-Martínez et al. 2010; Nasr 2020) and from acquisition of extended-spectrum $\beta$-lactamases (ESBLs) (Naas et al. 
2007). $\beta$-Lactamases with carbapenemase activity are most concerning, because the antibiotic resistance determinants may be found on plasmids and/or transposons that could be laterally transferred among bacteria. The rapid worldwide emergence of $\beta$-lactams and carbapenem-resistant $A$. baumannii strains shows the adaptation of this bacterium to selective environmental pressure (Peleg et al. 2008; Kempf and Rolain 2012; López-Durán et al. 2020). The emergence of MDR A. baumannii has increased the use of antibiotic colistin (Li et al. 2006; Tan et al. 2007; Kempf and Rolain 2012) and has unfortunately led to the discovery of colistinresistant strains (Kempf and Rolain 2012; Cai et al. 2012; Papathanakos et al. 2020).

In general, this bacterium is considered as a low virulence pathogen, but several virulence factors (Table 1), including adherence and invasion in host cells and host cell death (Choi et al. 2005, 2008), biofilm formation (Eze et al. 2018), capsular polysaccharides (Russo et al. 2013), phospholipase D (Zadeh Hosseingholi et al. 2014), serum resistance (Kim et al. 2009; Bolourchi et al. 2019) and iron acquisition (Zimbler et al. 2009) have been identified which make it a serious pathogen (Fig. 1). These virulence factors along with multidrug resistance trait make this pathogen create havoc, at least in hospitals and it is the emerging cause of nosocomial respiratory and urinary tract infections. Despite studies on several vaccine candidates to confer partial immunoprotection, there is no efficacious vaccine available to prevent $A$. baumannii infections at present.

Development of vaccines against $A$. baumannii is necessary to provide prophylactic protection for susceptible population of immunocompromised and patients in hospitals. As this is a nosocomial pathogen, every individual admitted in hospitals or undergoing antibiotic treatment has the potential risk to acquire infection. The incidence of chronic and persistent infections can be reduced through vaccination. The treatment of $A$. baumannii infections is very difficult due to the inherent resistance of $A$. baumannii to multiple antibiotics as various efflux pumps efficiently remove antibiotics from the bacterial cell that results in multidrug property of the A. baumannii. Another reason for antibiotic resistance is biofilm forming ability. In biofilms, the contact between antibiotics and surface of bacteria is hindered resulting in antibiotic failure. In addition, there are changes in the cell envelope reducing the permeability of the cell membrane to the antibiotics. In addition, the range of infections caused by Acinetobacter spp. and the potential to develop severe chronic infections in the immunocompromised individuals through the persistence ability make the need for vaccine crucial (Kaur et al. 2018).

\section{Active immunization}

Although A. baumannii causes nosocomial infections and it may not be suitable to immunize acute patients urgently requiring the protective treatment, but active immunization can evoke immunity and delay the onset of bacteremia to enhance the efficacy of antibiotic treatment in individuals at high risk (Table 2).

\section{Whole cell vaccines}

Whole cell vaccines (first generation), either live attenuated or killed, induce the immune system. Due to their ability to elicit a broad range of immune responses, these vaccines are considered ideal. They have been widely used against dreadful infectious diseases, such as cholera, mumps, measles and tuberculosis (Moyle 2015). Pathogenic strains are weakened by multiple passages in laboratory conditions or immunologically related microorganisms are used that do not use human as the target host. Live attenuated microbes do not cause any pathological or lethal effects in human body but they replicate and are recognized by human immune system

Table 1 Important virulence factors which can be used in vaccine development and their role in the pathogenesis of A. baumannii

\begin{tabular}{|c|c|c|c|}
\hline S. no & Virulence factor & Role & References \\
\hline 1 & OmpA & $\begin{array}{l}\text { Acts as porin, induces host cell apoptosis, antimicrobial } \\
\text { resistance and biofilm formation }\end{array}$ & Moon et al. 2012; Kwon et al. 2017; Nie et al. 2020a) \\
\hline 2 & $\begin{array}{l}\text { Biofilm associ- } \\
\text { ated protein } \\
\text { (BAP) }\end{array}$ & $\begin{array}{l}\text { In biofilm formation and involved in intercellular adhesion } \\
\text { within the mature biofilm }\end{array}$ & (Loehfelm et al. 2008; Brossard and Campagnari 2012) \\
\hline 3 & AdeABC & $\begin{array}{l}\text { Multidrug efflux complex involved in multidrug resistance } \\
\text { and biofilm formation }\end{array}$ & (Subhadra et al. 2019; Xu et al. 2019) \\
\hline 4 & Pili & A type IV pili system required for twitching motility & (Harding et al. 2013; Geisinger et al. 2019) \\
\hline 5 & CsuA/BABCDE & $\begin{array}{l}\text { Usher-chaperone fimbriae required for pili biogenesis and } \\
\text { biofilm formation }\end{array}$ & (Tomaras et al. 2003; Longo et al. 2014) \\
\hline 6 & PNAG & A surface polysaccharide involved in biofilm formation, & (Bentancor et al. 2012a; Geisinger et al. 2019) \\
\hline 7 & Capsule & $\begin{array}{l}\text { Provides protection desiccation and disinfection regimes as } \\
\text { well as host immune responses }\end{array}$ & (Russo et al. 2010; Geisinger et al. 2019; Hu et al. 2020) \\
\hline
\end{tabular}




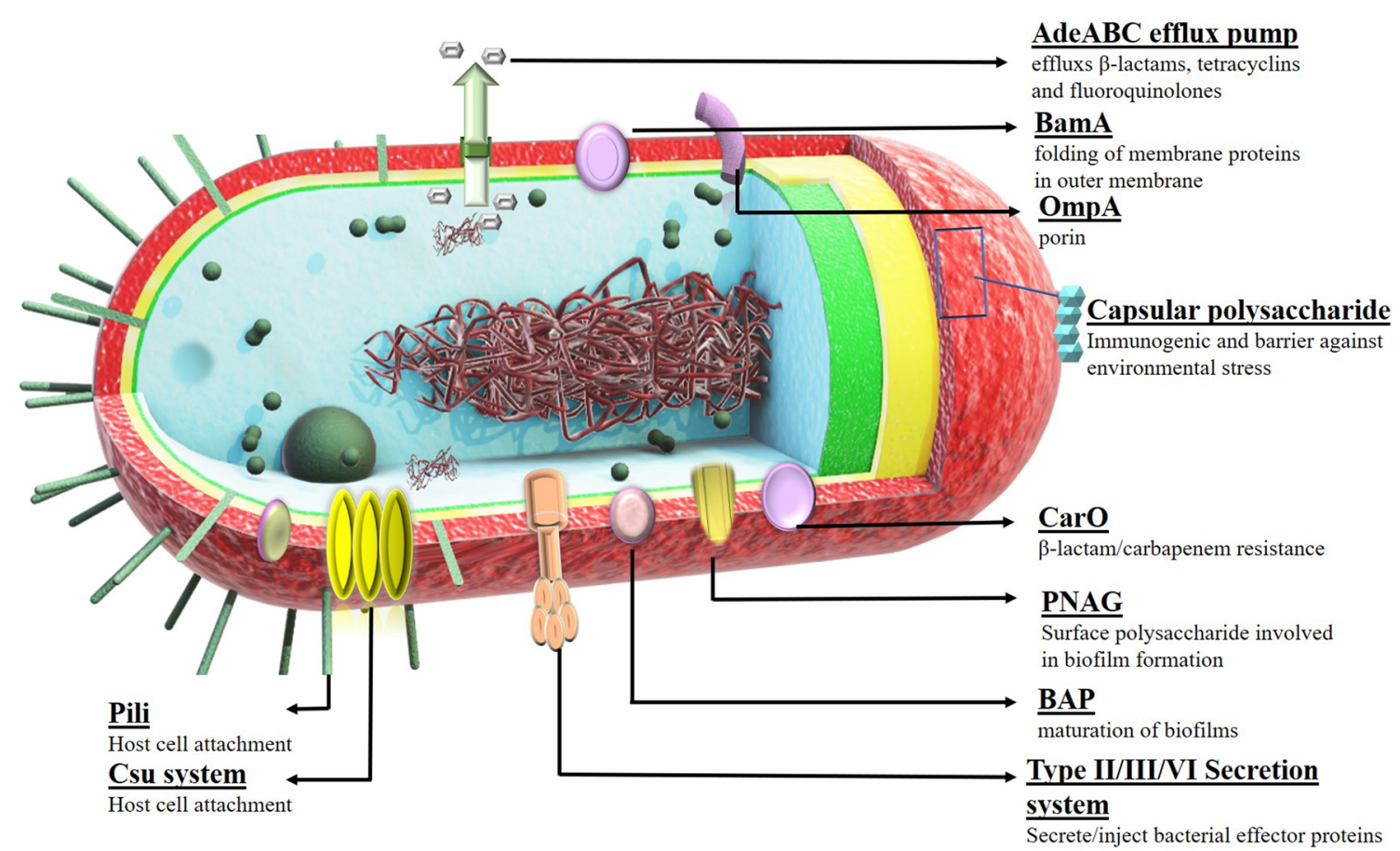

Fig. 1 A schematic illustration of virulence factors of A. baumannii with their roles. AdeABC RND efflux superfamily, BamA outer membrane protein assembly factor, OmpA outer membrane protein A,

as foreign invaders. By knocking out the virulence genes essential for pathogenesis, well defined weakened or attenuated live vaccines can be developed (Robbins and Robbins 1986; Nascimento and Leite 2012; Lin et al. 2015; Morais et al. 2019).

Killed whole cell vaccines consist of non-living pathogens that are unable to replicate and yet remain immunogenic in host which makes them extremely safe. This type of vaccine has been successfully used against anthrax, Q fever and whooping cough (Ada 2005). These vaccines elicit humoral immune response resulting in high concentration of neutralizing antibodies. Although killed whole cell vaccines are known to not stimulating the strong cell mediated immunity, resulting in multiple doses of vaccination for long lasting protection but they induce a broad immune response against multiple surface antigens. In case of A. baumannii, McConnell and Pachon reported high immunogenicity of whole cell vaccine inactivated by formalin as it produced significant antibody titer against multiple outer membrane proteins. Although this vaccine had contamination of high levels of LPS but it generated strong immune response resulting in reduction of bacterial loads in organs and reduced serum pro-inflammatory cytokine levels compared to unimmunized mice and protected mice from A. baumannii ATTC 19,606 and two clinical strains (McConnell and Pachón 2010). KuoLee et al. used inactivated whole cell vaccination approach against $A$. baumannii. In this study, a
CarO carbapenem associated resistance protein, $P N A G$ polysaccharide poly-N-acetylglucosamine, $B A P$ biofilm associated protein, $C s u$ Csu operon

clinical isolate of A. baumannii, LAC-4, causing $100 \%$ mortality in mice by acute pneumonia and bacteremia, was used for bacterial challenge. Intranasal immunization with formalin-killed A. baumannii LAC-4 cells resulted in high levels of IgG1 and IgG2 responses and ultimately clearing bacteria from lungs and serum (KuoLee et al. 2015). An inactivated whole-cell vaccine derived from antibiotic-exposed MDR $A$. baumannii (I-M28-47-114) (Shu et al. 2016) and radiation inactivated cells were found to be protective(Dollery et al. 2021).

\section{Single sub-unit vaccines}

Sub-unit vaccines contains minimal microbial components necessary to stimulate long lasting specific protective and/or therapeutic immune responses against the pathogen (Moyle and Toth 2013). However, preparation of subunit components as vaccines requires extremely stringent safety protocols as their preparation involves cultivation of live pathogenic bacteria in large scale culture.

\section{Protein candidates}

A. baumannii immunogenic proteins used are mostly extracellular or surface exposed proteins, such as outer membrane proteins (OMPs), porins, receptors, channels and other functional and structural components on the bacterial surface. 


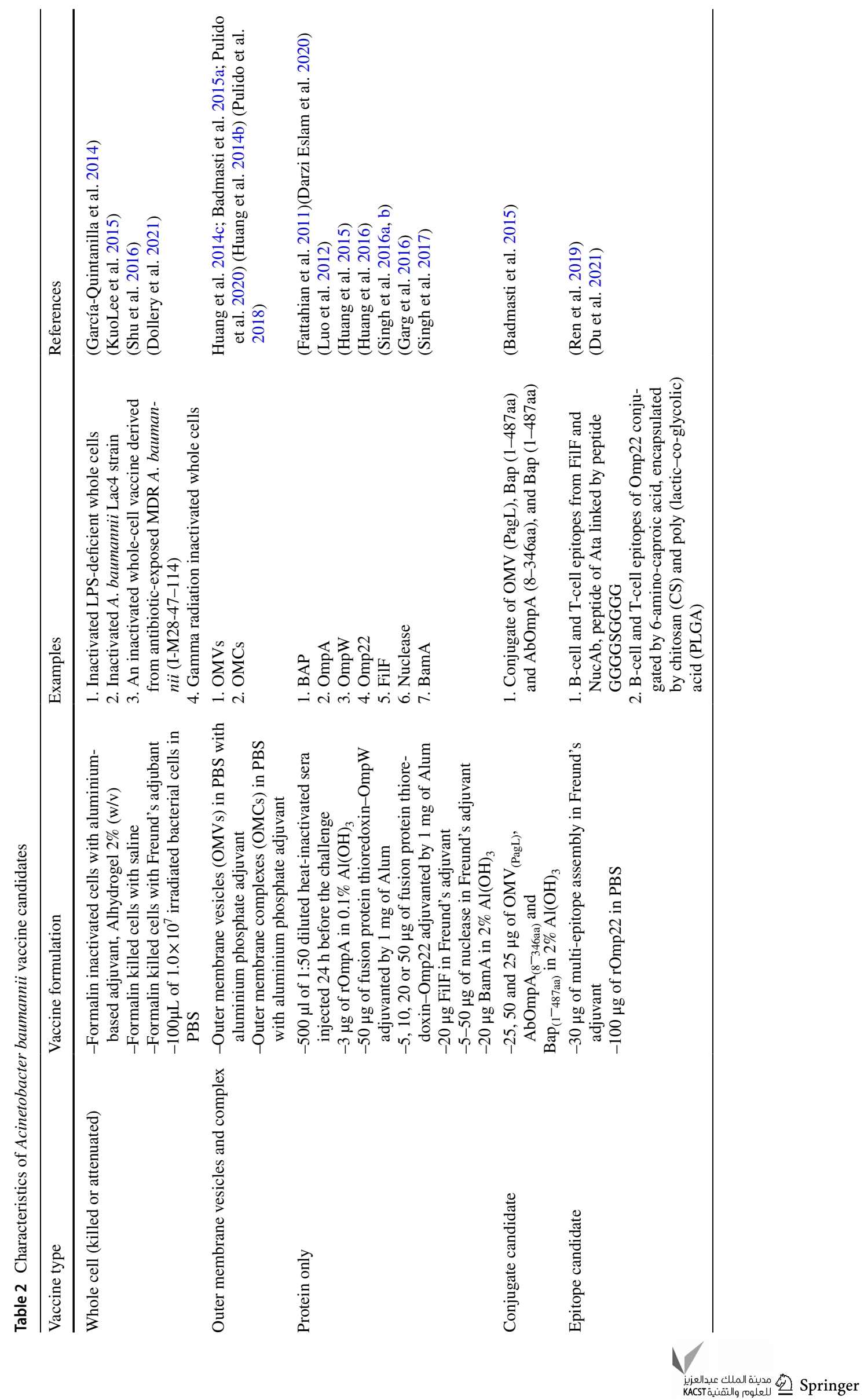


OmpA (Luo et al. 2012), Ata (Bentancor et al. 2012b), BamA (Singh et al. 2017), NucAb (Garg et al. 2016), FilF (Singh et al. 2016b), Bap (Fattahian et al. 2011), OmpW (Huang et al. 2015) and Omp22 (Huang et al. 2016) are the major outer membrane proteins that are antigenically conserved and surface exposed in sequenced strains and clinical isolates and immunization with these Omps as immunogens elicited opsonizing, cross reactive and protective antibodies in mouse pneumonia or sepsis model. Moreover, A. baumannii outer membrane proteins are highly conserved as compared to high heterogeneity of outer membrane vesicles or outer membrane complexes.

OmpA is most studied A. baumannii outer membrane protein and potential therapeutic target for A. baumannii infections(Choi et al. 2008; Gaddy et al. 2009; Park et al. 2012; Moon et al. 2012; Confer and Ayalew 2013; Samsudin et al. 2016; Jahangiri et al. 2017; Nie et al. 2020). Amount of vaccine candidate administered affects its immunology in the host. OmpA is well explored protein in A. baumannii and variations in its immunization doses was found to affect the antibody titer and immune responses. Larger vaccine doses (30-100 $\mu \mathrm{g})$ as compared to lower $(3 \mu \mathrm{g})$ was found to induce higher IgG and IgG subtypes, epitope restriction for IFN gamma producing lymphocytes, a polarized IL-4/ type 2 response, while lower doses induced lower antibody response and a balanced IFN- $\gamma$-IL-4 immune response (Lin et al. 2013). ompA gene was sequenced in six clinical strains of $A$. baumannii and found $99 \%$ identical. Immunization with recombinant outer membrane protein A resulted in high antibody titer, protected mice from infection and reduced bacterial load in various organs (Luo et al. 2012). Acinetobacter trimeric autotransporter or Ata protein plays a role in A. baumannii infections by acting as adhesion immobilizing collagen type IV and promotes biofilm formation. Immunization with Ata significantly reduced bacterial load in different organs of mice $24 \mathrm{~h}$ postinfection (Bentancor et al. 2012b). Chiang et al. analyzed whole proteome of $A$. baumannii, cloned 3 candidate proteins viz. OmpK, Ompp1 and FKIB in E. coli. Mice were immunized with these recombinant proteins along with complete/incomplete Freund's adjuvant and significant antibody titer was observed resulting in partial mice survival (60\%) after lethal bacterial challenge (Chiang et al. 2015). Similarly, OmpW protected mice from lethal bacterial challenge with $100 \%$ survival rates (Huang et al. 2015). A 22-kDa outer membrane protein of A. baumannii was found as a novel and safe antigen for developing antisera or effective vaccine to control $A$. baumannii infections (Huang et al. 2016). Omp22 was found more than $95 \%$ conserved in 851 reported $A$. baumannii strains. Recombinant Omp22 elicited significant titers of specific IgG in mice. Both active and passive immunizations with Omp22 suppressed the bacterial burdens in the organs, increased the survival rates of mice $(100 \%)$ and reduced the levels of serum cytokines and chemokines. In addition, Omp22 antiserum had efficient bactericidal activities against clinical $A$. baumannii isolates. In addition, high dose of purified protein $(500 \mu \mathrm{g})$ did not cause pathological changes in mice. BamA showed its immunoprotective potential against lethal doses of MDR A. baumannii and promising candidate for active and passive immunization (Singh et al. 2017). Recently, Omp87 showed significant immunoprotective potential against $A$. baumannii in sepsis model (Rasooli et al. 2020). The development of protein-based vaccine shows promising results as it relies on the identification of safe and effective vaccine candidates for the prevention of $A$. baumannii infections.

\section{Non-protein candidates}

Capsular polysaccharide is a well explored virulence factor, major component of the outer complex of A. baumannii and due to its surface accessibility, it has remained the widely characterized and tested vaccine candidate(Geisinger and Isberg 2015; Singh et al. 2019; Geisinger et al. 2019; Moubareck and Halat 2020). Russo et al. studied the effect of monoclonal antibodies against $\mathrm{K} 1$ capsular polysaccharide of A. baumannii in rat model. These monoclonal antibodies promoted in vitro neutrophil-mediated bactericidal activity and reduced post infection bacterial loads in various organs of rat. In addition, these monoclonal antibodies reacted to 13 out of 100 A. baumannii strains isolated from body sites and different geographic locations (Russo et al. 2013). However, capsule may interfere with the antiOMP antibodies (WangLin et al. 2017) but CPS-induced antibodies have been found to provide $55 \%$ protection against $A$. baumannii challenge in mouse (Yang et al. 2017).

\section{Outer membrane vesicles}

A. baumannii secrete outer membrane vesicles (OMVs) during growth (Jin et al. 2011). They are composed of phospholipids, proteins and lipopolysaccharides (LPS) forming spherical vesicles with diameter ranging from 20 to $300 \mathrm{~nm}$ (Ellis and Kuehn 2010). OMVs play role in the delivery of virulence factors to the host cells thus initiating the infection (Alaniz et al. 2007). The production of OMVs increases under stress and harsh conditions, such as infection (McBroom and Kuehn 2007). Exact mechanism of OMV formation is unknown but Deatherage et al. proposed and explained a model of OMV formation in Salmonella species (Deatherage et al. 2009). They described that OMVs are produced in cell envelope regions, where the density of outer membrane-peptidoglycan associations is temporarily decreased. They also found that outer membrane proteins present in OMVs have specific domains that could interact with peptidoglycan and could modulate OMV production. In 
addition, Salmonella mutants lacking few outer membrane proteins, such as OmpA, LppAb, and Pal, were able to produce more OMVs than wild type. In case of A. baumannii, OmpA was found to play important role in biogenesis of OMVs and protein composition (Moon et al. 2012).

OMVs have been tried as vaccine candidates against infections caused by A. baumannii. Jun et al. proposed OMVs as potent stimulators of innate immune response with membrane proteins in OMVs playing critical role in it. Immunization with OMVs successfully stimulated the pro-inflammatory response, recruitment of neutrophils and exudates in the lungs of neutropenic mice (Jun et al. 2013). Huang et al. studied immunoprotective efficacy of OMVs of a clinical isolate against MDR A. baumannii in both sepsis and pneumonia mice model. Immunization with these OMVs resulted in significant IgG antibody $(64,000$ titer, 21 days after 2 nd booster) response in female ICR mice. These OMVs were found effective in providing $100 \%$ mice survival due to decreased bacterial burden in organs, decreased pro-inflammatory cytokines and less damage to the organs after bacterial challenge (Huang et al. 2014). McConnell et al. have shown that OMV immunization reduced post-infection organ burden loads and increased survival after lethal challenge (McConnell et al. 2011b). Badmasti et al. isolated OMVs from A. baumannii expressing lipid A deacylase PagL and combined them with two other A. baumannii proteins viz. Bap and AbOmpA. These formulations induced robustly antibodies, Th1 and Th2 responses and protected mice from bacterial challenge (Badmasti et al. 2015). Recently, OMVs isolated from an Acinetobacter strain deficient in lipopolysaccharide (LPS) due to mutation in $\operatorname{lp} x D$ elicited immunity against infection and elicited antibody titers (IgG, IgG1, IgG2c and IgM) similar to the wild type (Pulido et al. 2018, 2020). These OMVs were highly immunogenic and their immunization resulted in significantly reduced post-infection spleen bacterial loads, serum IL-1 beta and IL-6 levels and provided $75 \%$ mice protection from bacterial challenge.

\section{Outer membrane complexes}

McConnell et al. analyzed the proteome of outer membrane complex of A. baumannii ATCC 19,606 and found 41 proteins associated with the cell surface. They used antibodies generated against multiple proteins in OMCs to recognize the surface proteins from clinical isolates (McConnell et al. 2011a). Immunization with OMCs reduced the bacterial load in organs and reduced the pro-inflammatory cytokines viz. IL-1 $\beta$, IL-6 and TNF- $\alpha$. Immunized mice showed increased survival rate after infection with ATCC 19,606 as well as with a pan-drug-resistant strain. Passive immunization with antisera raised against OMCs rescued the infected mice indicating the potential of OMC vaccines. However, preparation of vaccine using OMCs is tricky due to difficulties in standardization of levels of the multiple components of OMCs.

\section{Conjugate vaccines}

There are few reports of conjugate vaccines against $A$. baumannii. Gening et al. targeted Poly- $N$-Acetyl- $\beta-(1-6)-$ Glucosamine (PNAG), which is produced by several pathogens including A. baumannii, and prepared a conjugate of oligoglucosamines containing either 5- or 9-mer fully acetylated monosaccharides (5GlcNAc or 9GlcNAc) or 5- or 9-mer fully non acetylated monosaccharides $\left(5 \mathrm{GlcNH}_{2}\right.$ or 9 $\mathrm{GlcNH}_{2}$ ) and tetanus toxoid. This conjugate produced significant antibody titer which protected mice from $S$. aureus in skin abscesses murine model and from $E$. coli in lethal peritonitis model (Gening et al. 2010). Bentacor et al. demonstrated the efficacy of a conjugate of synthetic oligosaccharide and tetanus toxoid against a high PNAG producing A. baumannii strain. Antisera raised in rabbit against this conjugate successfully reduced the bacterial load in mice lungs resulting in high survival rates after lethal bacterial challenge. In addition, antiserum to conjugate showed significant opsonophagocytic activity against various $A$. baumannii clinical isolates (Bentancor et al. 2012a).

\section{Passive immunization}

Passive immunization has the potential to provide effective and prompt protection. Either in combination with antibiotic therapy or alone, antibacterial antibodies could treat the A. baumannii infections. Antibody preparations have been widely used to delay bacteremia onset by reducing the bacterial count in bronchoalveolar lavage fluid (BALF) or blood.

Several recombinant proteins of $A$. baumannii have been used to produce antisera that were assayed for the opsonophagocytic killing. Antisera generated by immunization with OMCs of $A$. baumannii have been shown to effectively rescue the infected mice (McConnell et al. 2011b). Inoculation with antisera $1 \mathrm{~h}$ after the bacterial infection resulted in survival of infected mice. Garg et al. have shown improved survival by passive immunization over active immunization using antisera raised against an outer membrane nuclease, NucAb. Active immunization with recombinant $\mathrm{NucAb}$ resulted in significant $\mathrm{IgG}$ titer of $1-5 \times 10^{5}$ resulting in $20 \%$ survival which increased to $40 \%$ after passive immunization (Garg et al. 2016).

Antisera against an outer membrane protein Omp22 exerted specific bactericidal activity at different dilutions $-39.8 \%$ at dilution of $10,24 \%$ at 100 and $11.8 \%$ at 1000-fold dilutions(Huang et al. 2016). The bactericidal activity was complement dependent as complement-inactivated antisera showed $22.2 \%$ killing by $10 \mathrm{X}$ dilutions. Removal of phagocytes from serum led to loss of killing

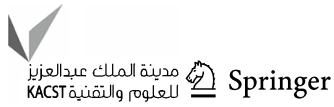


activity which proved that opsonophagocytic killing. BamA showed $40 \%$ mice protection from bacterial lethal challenge on passive immunization, mainly by the opsonophagocytic activity of serum (Singh et al. 2017).

\section{Reverse vaccinology for treating $A$. baumannii infections}

Reverse vaccinology is the use of genomic and proteomic information available in databases to predict potential vaccine candidate proteins against pathogens. In conventional vaccinology, pathogen is first cultured then its immunogenic components are identified, isolated and purified by laboratory protocols followed by their validation in animal models. Due to inability to work upon uncultivable pathogens, time consumption in experiments and serious biohazards associated with highly infectious pathogens, reverse vaccinology was discovered as a new approach to identify potential vaccine candidates. This technique requires complete proteomes of sequenced pathogens and online tools which predict the vaccine candidates and screen large number of isolates for homology (Rappuoli 2000, 2001; Sette and Rappuoli 2010; Singh et al. 2016a; Solanki and Tiwari 2018).

Reverse vaccinology represents a complete and successful example of computer-aided biotechnology providing vaccine candidates for most complex and difficult to treat infections (Vivona et al. 2008). Whole genome and proteome of pathogens are available and plethora of computations tools help in identification of potential vaccine candidate proteins out of them. NERVE (Vivona et al. 2006), Vaxign (He 2010), VaxiJen (Doytchinova and Flower 2007), Jenner-Predict (Jaiswal et al. 2013), VacSol (Rizwan et al. 2017) and Bowman-Heinson (Bowman et al. 2011; Heinson et al. 2017) and Vaxgin2 ((Ong et al. 2021)) are the major RV tools to predict potential vaccine candidates. Due to major limitations in conventional vaccinology, RV has become an initial and standard approach to search ideal vaccine candidates possessing certain characteristics (Rappuoli 2000; Singh et al. 2016a). The underlying principles in this approach are selection of proteins localized on cell surface as surface exposure of antigens is the most important requirement for the host-pathogen interaction. High level of antigen conservation is another fundamental requirement in this approach, as to provide broad spectrum immunity covering all the strains of pathogen is necessary. Other than these, vaccine candidate should contain minimum number of trans-membrane helices (less than 2), high adhesion probability, ability to bind to the MHC molecules, high conservation among the clinical strains and most important, its dissimilarity with human and mouse proteome to avoid the generation of autoimmune response by host. These characters can be easily predicted by online tools and servers. This approach has successfully led to identify antigens capable of eliciting protective immunity against $N$. meningitidis group B (Pizza et al. 2000; Kelly and Rappuoli 2005; Masignani et al. 2019).

Reverse vaccinology is highly successful in case of Acinetobacter baumannii (Table 3) (Chiang et al. 2015; Singh et al. 2016b, 2017; Hassan et al. 2016; Fereshteh et al. 2020). Using this approach, Chiang et al. analyzed the whole proteome of A. baumannii that provided several potential vaccine candidates. Out of these proteins, three were cloned and expressed in E. coli and immunization with these individually purified recombinant proteins conferred partial survival in A. baumannii mouse pneumonia model (Chiang et al. 2015). In silico analysis of several A. baumannii outer membrane proteins has highlighted their vaccine potential. Biofilm associated proteins present on the bacterial surface show high molecular weight, contain a core domain of tandem repeats and play critical role in bacterial infection processes. Rahber et al. analyzed these proteins using online tools and reported the four functional and conserved regions which could be effective antigens. Out of these regions, a construct serving as a potential agent for diagnostic test based on antigen-antibody interaction was described (Rahbar et al. 2010, 2012). BamA (beta barrel assembly machine protein) is also a potential vaccine candidate having several conserved B cell and T cell epitopes. BamA is an outer membrane protein belonging to Omp85 family conserved in all the Gram-negative bacteria. The B cell, MHC class I and MHC class II epitopes were predicted and docked with the HLA molecule to find their affinity towards HLA molecules prevalent in north Indian population (Singh et al. 2014).

An outer membrane putative pilus assembly protein, FilF, was identified using reverse vaccinology approach and FilF immunization significantly decreased bacterial load in lungs in A. baumannii pneumonia murine model resulting in decrease in pro-inflammatory cytokines, reduced infiltration of neutrophils in lung alveoli hence, improved survival (50\%) as compared to unimmunized infected mice (Singh et al. 2016b). Similarly, an A. baumannii outer membrane protein nuclease, $\mathrm{NucAb}$, was found to possess all the attributes of a promising vaccine candidate, such as outer membrane localization, one transmembrane helix only, high adhesin probability (0.53), non-homology to human proteins, totally conserved among all the sequenced $\mathrm{A}$. baumannii strains and presence of B-cell and T-cell epitopes binding with high affinity (percentile rank $\leq 1$ ) to HLA alleles prevalent in North Indian populations. Recombinant NucAb $(25 \mu \mathrm{g})$ immunization elicited high antibody titer $\left(1-5 \times 10^{5}\right)$ and reduced the bacterial load by $5 \log$ cycles in lungs, reduced pro-inflammatory cytokines (TNF- $\alpha$ and IL-6), whereas anti-inflammatory (IL-10) cytokine increased in serum and lungs. Active immunization resulted in $20 \%$ survival rate in mice which was improved to $40 \%$ with passive immunization (Garg et al. 2016). BamA (Singh et al. 


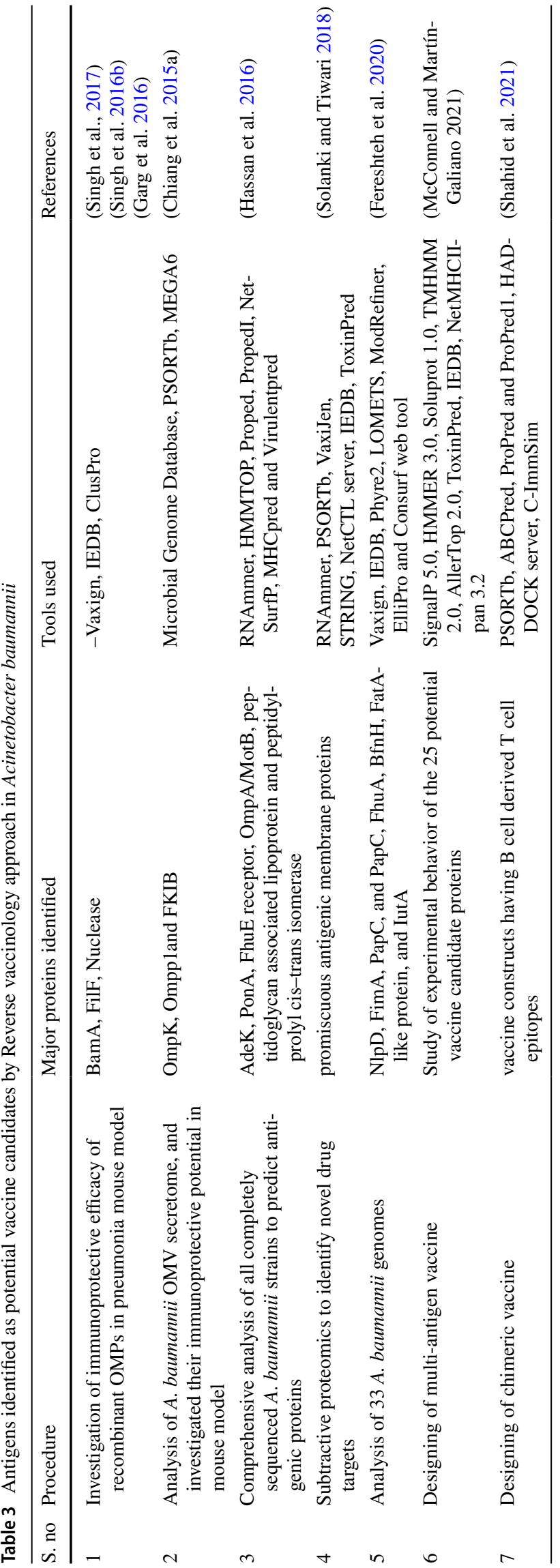

2017) and Omp87(Rasooli et al. 2020) are most promising vaccine candidates identified by Reverse Vaccinology as they elicited high antibody titer in mice, reduced cytokine levels and bacterial burden in organs and protected mice from lethal bacterial challenge by active and passive immunization. Recently, Fereshteh et al. analyzed A. baumannii proteomes using Reverse Vaccinology and predicted putative vaccine candidates mostly involved in cell division, pili or fimbria assembly and iron acquisition processes (Fereshteh et al. 2020).

\section{Epitope based broad spectrum vaccine}

Epitopes are the smallest molecular entities recognized by the host immune system. Developing epitope-based vaccine is challenging due to eminently polymorphic nature of MHC molecules and distinct frequencies of human leukocyte antigens (HLAs) (Sette and Fikes 2003; Parvizpour et al. 2020). A plethora of online tools are available now to predict T-cell epitopes and compare their population coverage in different geographical locations. Importantly, epitope-based vaccines can be designed to maximize the population coverage and minimizing the complexity or variability in human population. There is huge genomic and proteomic information available because of next generation sequencing that can be explored to identify the epitopes which are conserved among the strains of A. baumannii or Genus Acinetobacter and can be used to develop as broad-spectrum vaccine. Immune-dominant B and T-cell epitopes can generate robust immune response in host.

Whole proteomes of pathogens are screened for highly conserved surface exposed proteins and then, B cell and T cells are predicted using online epitope prediction tools. BamA (Singh et al.), Phospholipase D(Zadeh Hosseingholi et al. 2014), NucAb (Garg et al. 2016), FilF (Singh et al. 2016b), TolB (Song et al. 2018), Omp34 (Jahangiri et al. 2018), Ton-B dependent copper receptor (Abdollahi et al. 2018), Polysaccharide export outer membrane protein (Ahmad and Azam 2018), Chaperone-usher pathway protein B, CsuB (Ahmad and Azam 2018), Iron regulated proteins(Bazmara et al. 2019), Rhs(Ahmad et al. 2019) and fimbrial biogenesis outer membrane usher protein, FimD (Ahmad et al. 2019) are the A. baumannii proteins used for epitope prediction. However, epitope vaccine candidates have been designed as chimeric construct containing more than one epitope or combination of B or T cell epitopes from different proteins. Ahmad et al. investigated a tigecyclineresistant $A$. baumannii strain and predicted BamA, FimD and $\mathrm{Rhs}$ from core proteome as surface proteins, essential, localized at the pathogen surface, non-homologous to humans and mice. Epitopes FPLNDKPGD (BamA), FVHAEEAAA (FimD) and YVVAGTAAA (Rhs) were predicted which had high affinity for the prevalent alleles in human populations.

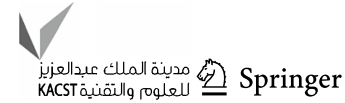


These epitopes were linked, attached to an adjuvant to enhance its antigenicity and docked with TLR4 receptor showing high affinity (Ahmad et al. 2019). Omp34 is present in $>1600$ A. baumannii strains with $>98 \%$ identity and its antigen construct was designed as antigen with high epitope density in which copies of antigenic peptides were increased by replacing non-antigen sequences(Jahangiri et al. 2018). Ren et al, 2019 constructed multi-epitope assembly peptide by linking two B-cell epitopes of Ata, one CD4 + T-cell epitope from FilF and two B-cell epitopes and one $\mathrm{CD}+$ epitope from NucAb and its immunoprotective efficacy was investigated in mice and found as promising vaccine candidate (Ren et al. 2019). Vaccine candidate proteins obtained by in silico analysis of $A$. baumannii proteomes are subjected to conservation analysis and sequential epitope mapping (Moriel et al. 2013; Chiang et al. 2015; Garg et al. 2016; Singh et al. 2016b, 2017; Hassan et al. 2016; Ren et al. 2019; Fereshteh et al. 2020; Du et al. 2021; Shahid et al. 2021).

\section{Conclusion}

Vaccine development against fierce infectious microorganisms has remained one of the great human achievements. It has primarily focused on the pathogenesis of pathogen based on its virulence factors causing the infection. In addition, constant evolution of multidrug-resistant strains is challenging the antibiotic regime and indicating the vaccine development as an appropriate and effective treatment option. Current recombinant immunization strategies target a single or multiple outer membrane proteins which are easy to prepare, safe as there is no risk of pathogen reverting back to its virulent form and very few adverse effects as compared to other forms of vaccination. Recombinant vaccines are designed for broad range of protection by selecting only those proteins which are conserved throughout the strains of a specific species or species of a particular genus. Conservation analysis of these proteins are performed either by in silico analysis using genomic and proteomic information or by checking them in clinical isolates using polymerase chain reaction (PCR). Completely and partially sequenced strains of $A$. baumannii can be screened for proteins conserved in maximum of strains and these candidates can be evaluated for their vaccine potential. Moreover, identifying specific host immune pathways induced by $A$. baumannii infection or immunization will facilitate the discovery of new and potential immunoprotective candidates to help eliminate this emerging public health crisis. Multidrug-resistant A. baumannii is a major source of concern and constitutes a serious therapeutic problem as use of newer generation antibiotics is expensive. Better hygienic conditions and sanitation, routine microbiological surveillance and proper in vitro testing prior to the use of antibiotic may help in control, prevention and treatment of these infections. In addition, there is a dire need for accurate identification of these pathogens to reduce outbreaks.

\section{Future perspective}

Vaccine development against multidrug-resistant pathogens have shown significant potential to reduce the clinical burden, mortality and morbidity caused by them. Preparing the host for incoming nosocomial pathogens may be the most promising treatment option as adaptive immune response (APCs, B cells and T cells) leads to protection through cellular or humoral immunity. Genomic and proteomic data available are being explored to find out broad spectrum vaccine candidates by analyzing multiple strains at once. The dearth of effective therapeutics to treat multidrug $A$. baumannii has energized the researchers to seek novel approaches and ingenious strategies. Reverse vaccinology is such a time saving approach to predict potential vaccine candidates exploiting huge bioinformatic data. Moreover, several vaccine development attempts have provided important details about $A$. baumannii's antimicrobial resistance patterns, diversity, active/passive vaccination and animal infection model development that can assist in more potent and efficacious vaccine development against $A$. baumannii.

Funding This research did not receive any specific grant from funding agencies in the public, commercial, or not-for-profit sectors.

\section{Declarations}

Conflict of interest The authors report no conflict of interest.

\section{References}

Abdi SN, Ghotaslou R, Ganbarov K et al (2020) Acinetobacter baumannii efflux pumps and antibiotic resistance. Infect Drug Resist 13:423-434

Abdollahi S, Rasooli I, Mousavi Gargari SL (2018) An in silico structural and physicochemical characterization of TonB-dependent copper receptor in A. baumannii. Microb Pathog 118:18-31. https://doi.org/10.1016/j.micpath.2018.03.009

Ada G (2005) Overview of vaccines and vaccination. Mol Biotechnol 29:255-271

Ahmad S, Azam SS (2018) A novel approach of virulome based reverse vaccinology for exploring and validating peptide-based vaccine candidates against the most troublesome nosocomial pathogen: Acinetobacter baumannii. J Mol Graph Model 83:1-11. https:// doi.org/10.1016/j.jmgm.2018.04.020

Ahmad S, Ranaghan KE, Azam SS (2019) Combating tigecycline resistant Acinetobacter baumannii: A leap forward towards multi-epitope based vaccine discovery. Eur J Pharm Sci 132:117. https://doi.org/10.1016/j.ejps.2019.02.023 
Alaniz RC, Deatherage BL, Lara JC, Cookson BT (2007) Membrane vesicles are immunogenic facsimiles of Salmonella typhimurium that potently activate dendritic cells, prime $\mathrm{B}$ and $\mathrm{T}$ cell responses, and stimulate protective immunity in vivo. J Immunol 179:7692-7701. https://doi.org/10.4049/jimmunol.179.11.7692

Azim A, Dwivedi M, Rao PB et al (2010) Epidemiology of bacterial colonization at intensive care unit admission with emphasis on extended-spectrum $\beta$-lactamase- and metallo- $\beta$ - lactamase-producing Gram-negative bacteria - An Indian experience. J Med Microbiol 59:955-960. https://doi.org/10.1099/jmm.0.018085-0

Badmasti F, Ajdary S, Bouzari S et al (2015) Immunological evaluation of OMV(PagL)+Bap(1-487aa) and AbOmpA(8-346aa)+Bap(1487aa) as vaccine candidates against Acinetobacter baumannii sepsis infection. Mol Immunol 67:552-558. https://doi.org/10. 1016/j.molimm.2015.07.031

Banerjee T, Mishra A, Das A et al (2018) High prevalence and endemicity of multidrug resistant Acinetobacter spp. in intensive care unit of a tertiary care hospital, Varanasi. India J Pathog 2018:1-8. https://doi.org/10.1155/2018/9129083

Bazmara H, Rasooli I, Jahangiri A et al (2019) Antigenic properties of iron regulated proteins in Acinetobacter baumannii: an in silico approach. Int J Pept Res Ther 25:205-213. https://doi.org/10. 1007/s10989-017-9665-6

Bentancor LV, O'malley JM, Bozkurt-Guzel C, et al (2012a) Polyn-acetyl- $\beta$-(1-6)-glucosamine is a target for protective immunity against Acinetobacter baumannii infections. Infect Immun 80:651-656. https://doi.org/10.1128/IAI.05653-11

Bentancor LV, Routray A, Bozkurt-Guzel C et al (2012b) Evaluation of the trimeric autotransporter ata as a vaccine candidate against Acinetobacter baumannii infections. Infect Immun 80:33813388. https://doi.org/10.1128/IAI.06096-11

Bolourchi N, Shahcheraghi F, Shirazi AS et al (2019) Immunogenic reactivity of recombinant $\mathrm{PKF}$ and AbOmpA proteins as serum resistance factors against sepsis of Acinetobacter baumannii. Microb Pathog 131:9-14. https://doi.org/10.1016/j.micpath.2019.03.031

Bowman BN, McAdam PR, Vivona S et al (2011) Improving reverse vaccinology with a machine learning approach. Vaccine 29:8156-8164. https://doi.org/10.1016/j.vaccine.2011.07.142

Brink AJ (2019) Epidemiology of carbapenem-resistant Gram-negative infections globally. Curr Opin Infect Dis 32:609-616. https://doi. org/10.1097/QCO.0000000000000608

Brotfain E, Borer A, Koyfman L et al (2017) Multidrug resistance acinetobacter bacteremia secondary to ventilator-associated pneumonia: risk factors and outcome. J Intensive Care Med 32:528-534. https://doi.org/10.1177/0885066616632193

Cai Y, Chai D, Wang R et al (2012) Colistin resistance of Acinetobacter baumannii: clinical reports, mechanisms and antimicrobial strategies. J Antimicrob Chemother 67:1607-1615. https://doi. org/10.1093/jac/dks084

Chiang MH, Sung WC, Lien SP et al (2015) Identification of novel vaccine candidates against Acinetobacter baumannii using reverse vaccinology. Hum Vaccines Immunother 11:1065-1073. https:// doi.org/10.1080/21645515.2015.1010910

Choi CH, Lee EY, Lee YC et al (2005) Outer membrane protein 38 of Acinetobacter baumannii localizes to the mitochondria and induces apoptosis of epithelial cells. Cell Microbiol 7:11271138. https://doi.org/10.1111/j.1462-5822.2005.00538.x

Choi CH, Lee JS, Lee YC et al (2008) Acinetobacter baumannii invades epithelial cells and outer membrane protein A mediates interactions with epithelial cells. BMC Microbiol. https://doi.org/10. 1186/1471-2180-8-216

Čiginskienė A, Dambrauskienė A, Rello J, Adukauskienė D (2019) Ventilator-associated pneumonia due to drug-resistant Acinetobacter baumannii: Risk factors and mortality relation with resistance profiles, and independent predictors of in-hospital mortality. Med. https://doi.org/10.3390/medicina55020049
Confer AW, Ayalew S (2013) The OmpA family of proteins: Roles in bacterial pathogenesis and immunity. Vet Microbiol 163:207-222

Corvec S, Caroff N, Espaze E et al (2003) AmpC cephalosporinase hyperproduction in Acinetobacter baumannii clinical strains. J Antimicrob Chemother 52:629-635. https://doi.org/10.1093/jac/dkg407

Darzi Eslam E, Darvish Alipour Astaneh S, Rasooli I et al (2020) Passive immunization with chitosan-loaded biofilm-associated protein against Acinetobacter baumannii murine infection model. Gene Reports 20:100708. https://doi.org/10.1016/J.GENREP. 2020.100708

Deatherage BL, Lara JC, Bergsbaken T et al (2009) Biogenesis of bacterial membrane vesicles. Mol Microbiol 72:1395-1407. https:// doi.org/10.1111/j.1365-2958.2009.06731.x

Dijkshoorn L, Nemec A, Seifert H (2007) An increasing threat in hospitals: Multidrug-resistant Acinetobacter baumannii. Nat Rev Microbiol 5:939-951

Dollery SJ, Zurawski DV, Gaidamakova EK et al (2021) Radiationinactivated Acinetobacter baumannii vaccine candidates. Vaccines 9:96. https://doi.org/10.3390/VACCINES9020096

Doytchinova IA, Flower DR (2007) VaxiJen: A server for prediction of protective antigens, tumour antigens and subunit vaccines. BMC Bioinform 8:4. https://doi.org/10.1186/1471-2105-8-4

Du X, Xue J, Jiang M et al (2021) A multiepitope peptide, rOmp22, encapsulated in chitosan-PLGA nanoparticles as a candidate vaccine against Acinetobacter baumannii infection. Int J Nanomedicine 16:1819. https://doi.org/10.2147/IJN.S296527

Ellis TN, Kuehn MJ (2010) Virulence and immunomodulatory roles of bacterial outer membrane vesicles. Microbiol Mol Biol Rev 74:81-94. https://doi.org/10.1128/mmbr.00031-09

Espinal P, Martí S, Vila J (2012) Effect of biofilm formation on the survival of Acinetobacter baumannii on dry surfaces. J Hosp Infect 80:56-60. https://doi.org/10.1016/j.jhin.2011.08.013

Eze EC, Chenia HY, El Zowalaty ME (2018) Acinetobacter baumannii biofilms: Effects of physicochemical factors, virulence, antibiotic resistance determinants, gene regulation, and future antimicrobial treatments. Infect Drug Resist 11:2277-2299

Falagas ME, Karveli EA (2007) The changing global epidemiology of Acinetobacter baumannii infections: A development with major public health implications. Clin Microbiol Infect 13:117-119

Fattahian Y, Rasooli I, Mousavi Gargari SL et al (2011) Protection against Acinetobacter baumannii infection via its functional deprivation of biofilm associated protein (Bap). Microb Pathog 51:402-406. https://doi.org/10.1016/j.micpath.2011.09.004

Fereshteh S, Abdoli S, Shahcheraghi F et al (2020) New putative vaccine candidates against Acinetobacter baumannii using the reverse vaccinology method. Microb Pathog 143:104114. https:// doi.org/10.1016/j.micpath.2020.104114

García-Quintanilla M, Pulido MR, Pachón J, McConnell MJ (2014) Immunization with lipopolysaccharide-deficient whole cells provides protective immunity in anexperimental mouse model of Acinetobacter baumannii infection. PLoS One. https://doi.org/ 10.1371/journal.pone. 0114410

Gaddy JA, Tomaras AP, Actis LA (2009) The Acinetobacter baumannii 19606 OmpA protein plays a role in biofilm formation on abiotic surfaces and in the interaction of this pathogen with eukaryotic cells. Infect Immun 77:3150-3160. https://doi.org/10.1128/IAI.00096-09

Garg N, Singh R, Shukla G et al (2016) Immunoprotective potential of in silico predicted Acinetobacter baumannii outer membrane nuclease, NucAb. Int J Med Microbiol 306:1-9. https://doi.org/ 10.1016/j.ijmm.2015.10.005

Geisinger E, Isberg RR (2015) Antibiotic modulation of capsular exopolysaccharide and virulence in Acinetobacter baumannii. PLoS Pathog. https://doi.org/10.1371/journal.ppat.1004691

Geisinger E, Huo W, Hernandez-Bird J, Isberg RR (2019) Acinetobacter baumannii : envelope determinants that control

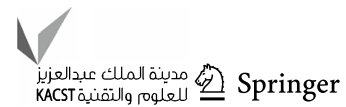


drug resistance, virulence, and surface variability. Annu Rev Microbiol 73:481-506. https://doi.org/10.1146/annur ev-micro-020518-115714

Gening ML, Maira-Litrán T, Kropec A et al (2010) Synthetic $\beta-(1 \rightarrow 6)$ linked $\mathrm{N}$-acetylated and nonacetylated oligoglucosamines used to produce conjugate vaccines for bacterial pathogens. Infect Immun 78:764-772. https://doi.org/10.1128/IAI.01093-09

Harding CM, Tracy EN, Carruthers MD et al (2013) Acinetobacter baumannii strain M2 produces type IV Pili which play a role in natural transformation and twitching motility but not surface-associated motility. MBio. https://doi.org/10.1128/mBio. 00360-13

Hassan A, Naz A, Obaid A et al (2016) Pangenome and immuno-proteomics analysis of Acinetobacter baumannii strains revealed the core peptide vaccine targets. BMC Genomics 17:1-25. https:// doi.org/10.1186/s12864-016-2951-4

He Y, Xiang Z, Mobley HL (2010) Vaxign: the first web-based vaccine design program for reverse vaccinology and applications for vaccine development. J Biomed Biotechnol. https://doi.org/ $10.1155 / 2010 / 297505$

Heinson AI, Gunawardana Y, Moesker B et al (2017) Enhancing the biological relevance of machine learning classifiers for reverse vaccinology. Int J Mol Sci. https://doi.org/10.3390/ijms18020312

Holt K, Kenyon JJ, Hamidian M et al (2016) Five decades of genome evolution in the globally distributed, extensively antibiotic-resistant Acinetobacter baumannii global clone 1. Microb Genomics 2:1-16. https://doi.org/10.1099/mgen.0.000052

Huang W, Yao Y, Long Q et al (2014) Immunization against multidrug-resistant Acinetobacter baumannii effectively protects mice in both pneumonia and sepsis models. PLoS ONE 9:e100727. https://doi.org/10.1371/journal.pone.0100727

Huang W, Wang S, Yao Y et al (2015) OmpW is a potential target for eliciting protective immunity against Acinetobacter baumannii infections. Vaccine 33:4479-4485. https://doi.org/10.1016/j. vaccine.2015.07.031

Huang W, Yao Y, Wang S et al (2016) Immunization with a 22-kDa outer membrane protein elicits protective immunity to multidrugresistant Acinetobacter baumannii. Sci Rep 6:1-12. https://doi. org/10.1038/srep20724

Hu L, Shi Y, Xu Q et al (2020) Capsule thickness, not biofilm formation, gives rise to mucoid acinetobacter baumannii phenotypes that are more prevalent in long-term infections: A study of clinical isolates from a hospital inchina. Infect Drug Resist 13:99-109. https://doi.org/10.2147/IDR.S230178

Jahangiri A, Rasooli I, Owlia P et al (2017) In silico design of an immunogen against Acinetobacter baumannii based on a novel model for native structure of Outer membrane protein A. Microb Pathog 105:201-210. https://doi.org/10.1016/j.micpath.2017.02. 028

Jahangiri A, Rasooli I, Owlia P et al (2018) Highly conserved exposed immunogenic peptides of Omp34 against Acinetobacter baumannii: an innovative approach. J Microbiol Methods 144:79-85. https://doi.org/10.1016/j.mimet.2017.11.008

Jaiswal V, Chanumolu SK, Gupta A et al (2013) Jenner-predict server: Prediction of protein vaccine candidates (PVCs) in bacteria based on host-pathogen interactions. BMC Bioinform. https://doi.org/ 10.1186/1471-2105-14-211

Jin JS, Kwon SO, Moon DC et al (2011) Acinetobacter baumannii secretes cytotoxic outer membrane protein a via outer membrane vesicles. PLoS ONE. https://doi.org/10.1371/journal.pone.00170 27

Jun SH, Lee JH, Kim BR et al (2013) Acinetobacter baumannii outer membrane vesicles elicit a potent innate immune response via membrane proteins. PLoS ONE. https://doi.org/10.1371/journ al.pone. 0071751
Kalal BS, Chandran SP, Yoganand R, Nagaraj S (2020) Molecular characterization of carbapenem-resistant Acinetobacter baumannii strains from a tertiary care center in South India. Infectio 24:27-34. https://doi.org/10.22354/in.v24i1.824

Karthika RU, Rao RS, Sahoo S et al (2009) Phenotypic and genotypic assays for detecting the prevalence of metallo- $\beta$-lactamases in clinical isolates of Acinetobacter baumannii from a South Indian tertiary care hospital. J Med Microbiol 58:430-435. https://doi. org/10.1099/jmm.0.002105-0

Kaur A, Sharma P, Capalash N (2018) Curcumin alleviates persistence of Acinetobacter baumannii against colistin. Sci Rep 8:1-11. https://doi.org/10.1038/s41598-018-29291-z

Kelly DF, Rappuoli R (2005) Reverse vaccinology and vaccines for serogroup B Neisseria meningitidis. Adv Exp Med Biol 568:217-223

Kempf M, Rolain JM (2012) Emergence of resistance to carbapenems in Acinetobacter baumannii in Europe: Clinical impact and therapeutic options. Int J Antimicrob Agents 39:105-114

Kim SW, Choi CH, Moon DC et al (2009) Serum resistance of Acinetobacter baumannii through the binding of factor $\mathrm{H}$ to outer membrane proteins. FEMS Microbiol Lett 301:224-231. https://doi.org/10.1111/j.1574-6968.2009.01820.x

KuoLee R, Harris G, Yan H et al (2015) Intranasal immunization protects against Acinetobacter baumannii-associated pneumonia in mice. Vaccine 33:260-267. https://doi.org/10.1016/j. vaccine.2014.02.083

Kwon II H, Kim S, Oh MH et al (2017) Outer membrane protein A contributes to antimicrobial resistance ofAcinetobacter baumannii through the OmpA-like domain. J Antimicrob Chemother 72:3012-3015. https://doi.org/10.1093/jac/dkx257

Li J, Rayner CR, Nation RL et al (2006) Heteroresistance to colistin in multidrug-resistant Acinetobacter baumannii. Antimicrob Agents Chemother 50:2946-2950. https://doi.org/10.1128/ AAC.00103-06

Lin L, Tan B, Pantapalangkoor P et al (2013) Acinetobacter baumannii rOmpA vaccine dose alters immune polarization and immunodominant epitopes. Vaccine 31:313-318. https://doi. org/10.1016/j.vaccine.2012.11.008

Lin IYC, Van TTH, Smooker PM (2015) Live-attenuated bacterial vectors: Tools for vaccine and therapeutic agent delivery. Vaccines 3:940-972

Loehfelm TW, Luke NR, Campagnari AA (2008) Identification andcharacterization of an Acinetobacter baumannii biofilm-associated protein. J Bacteriol 190:1036-1044. https://doi.org/10.1128/ JB.01416-0

Longo F, Vuotto C, Donelli G (2014) Longo 2014. New Microbiol 37:119-127

López-Durán PA, Fonseca-Coronado S, Lozano-Trenado LM et al (2020) Nosocomial transmission of extensively drug resistant Acinetobacter baumannii strains in a tertiary level hospital. PLoS ONE 15:e0231829. https://doi.org/10.1371/journal.pone. 0231829

Luo G, Lin L, Ibrahim AS et al (2012) Active and passive immunization protects against lethal, extreme drug resistant-Acinetobacter baumannii infection. PLoS ONE. https://doi.org/10.1371/ journal.pone.0029446

Masignani V, Pizza M, Moxon ER (2019) The development of a vaccine against Meningococcus B using reverse vaccinology. Front Immunol. 10:751

McBroom AJ, Kuehn MJ (2007) Release of outer membrane vesicles by Gram-negative bacteria is a novel envelope stress response. Mol Microbiol 63:545-558. https://doi.org/10.1111/j.13652958.2006.05522.x

McConnell MJ, Pachón J (2010) Active and passive immunization against Acinetobacter baumannii using an inactivated whole 
cell vaccine. Vaccine 29:1-5. https://doi.org/10.1016/j.vacci ne.2010.10.052

McConnell MJ, Domínguez-Herrera J, Smani Y et al (2011a) Vaccination with outer membrane complexes elicits rapid protective immunity to multidrug-resistant Acinetobacter baumannii. Infect Immun 79:518-526. https://doi.org/10.1128/IAI. 00741-10

McConnell MJ, Rumbo C, Bou G, Pachón J (2011b) Outer membrane vesicles as an acellular vaccine against Acinetobacter baumannii. Vaccine 29:5705-5710. https://doi.org/10.1016/j.vaccine.2011. 06.001

McConnell MJ, Martín-Galiano AJ (2021) Designing Multi-Antigen Vaccines Against Acinetobacter baumannii Using Systemic Approaches. Front Immunol 0:1223. https://doi.org/10.3389/ FIMMU.2021.666742

Meumann EM, Anstey NM, Currie BJ et al (2019) Genomic epidemiology of severe community-onset Acinetobacter baumannii infection. Microb Genom 5:1-13. https://doi.org/10.1099/mgen.0. 000258

Moon DC, Choi CH, Lee JH et al (2012) Acinetobacter baumannii outer membrane protein a modulates the biogenesis of outer membrane vesicles. J Microbiol 50:155-160. https://doi.org/10. 1007/s12275-012-1589-4

Morais V, Texeira E, Suarez N (2019) Next-generation whole-cell pneumococcal vaccine. Vaccines 7:151. https://doi.org/10.3390/ vaccines7040151

Moriel DG, Beatson SA, Wurpel DJ et al (2013) Identification of novel vaccine candidates against multidrug-resistant Acinetobacter baumannii. PLoS ONE. https://doi.org/10.1371/journal.pone. 0077631

Moubareck CA, Halat DH (2020) Insights into Acinetobacter baumannii: A review of microbiological, virulence, and resistance traits in a threatening nosocomial pathogen. Antibiotics 9

Moyle PM, Toth I (2013) Modern subunit vaccines: development, components, and research opportunities. ChemMedChem 8:360-376. https://doi.org/10.1002/cmdc.201200487

Moyle PM (2015) Progress in vaccine development. Curr Protoc Microbiol. https://doi.org/10.1002/9780471729259.mc1801s36

Naas T, Kernbaum S, Allali S, Nordmann P (2007) Multidrug-resistant Acinetobacter baumannii, Russia [15]. Emerg Infect Dis 13:669-671

Nascimento IP, Leite LCC (2012) Recombinant vaccines and the development of new vaccine strategies. Brazilian J Med Biol Res 45:1102-1111

Nasr P (2020) Genetics, epidemiology, and clinical manifestations of multidrug-resistant Acinetobacter baumannii. J Hosp Infect 104:4-11

Nguyen M, Joshi SG (2021) Carbapenem resistance in Acinetobacter baumannii, and their importance in hospital-acquired infections: a scientific review. J Appl Microbiol. https://doi.org/10.1111/ JAM. 15130

Nie D, Hu Y, Chen Z et al (2020) Outer membrane protein A (OmpA) as a potential therapeutic target for Acinetobacter baumannii infection. J Biomed Sci 27:26

Odsbu I, Khedkar S, Khedkar U et al (2018) High proportions of multidrug-resistant acinetobacter spp. Isolates in a district in Western India: A four-year antibiotic susceptibility study of clinical isolates. Int J Environ Res Public Health. https://doi.org/10.3390/ ijerph15010153

Ong E, Cooke MF, Huffman A et al (2021) Vaxign2: the second generation of the first Web-based vaccine design program using reverse vaccinology and machine learning. Nucleic Acids Res 49:W671. https://doi.org/10.1093/NAR/GKAB279

Papathanakos G, Andrianopoulos I, Papathanasiou A et al (2020) Colistin-resistant Acinetobacter baumannii bacteremia: a serious threat for critically Ill patients. Microorganisms 8:287. https:// doi.org/10.3390/microorganisms 8020287

Park JS, Lee WC, Yeo KJ et al (2012) Mechanism of anchoring of OmpA protein to the cell wall peptidoglycan of the gram-negative bacterial outer membrane. FASEB J 26:219-228. https://doi. org/10.1096/fj.11-188425

Parvizpour S, Pourseif MM, Razmara J et al (2020) Epitope-based vaccine design: a comprehensive overview of bioinformatics approaches. Drug Discov Today. https://doi.org/10.1016/j.drudis. 2020.03.006

Peleg AY, Seifert H, Paterson DL (2008) Acinetobacter baumannii: Emergence of a successful pathogen. Clin Microbiol Rev 21:538-582

Pizza M, Scarlato V, Masignani V et al (2000) Identification of vaccine candidates against serogroup B meningococcus by wholegenome sequencing. Science (-80) 287:1816-1820. https://doi. org/10.1126/science.287.5459.1816

Pormohammad A, Mehdinejadiani K, Gholizadeh P et al (2020) Global prevalence of colistin resistance in clinical isolates of Acinetobacter baumannii: A systematic review and meta-analysis. Microb Pathog 139:103887. https://doi.org/10.1016/j.micpath. 2019.103887

Pulido MR, García-Quintanilla M, Pachón J, McConnell MJ (2018) Immunization with lipopolysaccharide-free outer membrane complexes protects against Acinetobacter baumannii infection. Vaccine 36:4153-4156. https://doi.org/10.1016/J.VACCINE. 2018.05.113

Pulido MR, García-Quintanilla M, Pachón J, McConnell MJ (2020) A lipopolysaccharide-free outer membrane vesicle vaccine protects against Acinetobacter baumannii infection. Vaccine 38:719-724. https://doi.org/10.1016/j.vaccine.2019.11.043

Rahbar MR, Rasooli I, Mousavi Gargari SL et al (2010) In silico analysis of antibody triggering biofilm associated protein in Acinetobacter baumannii. J Theor Biol 266:275-290. https://doi.org/10. 1016/j.jtbi.2010.06.014

Rahbar MR, Rasooli I, Gargari SLM et al (2012) A potential in silico antibody-antigen based diagnostic test for precise identification of Acinetobacter baumannii. J Theor Biol 294:29-39. https://doi. org/10.1016/j.jtbi.2011.10.026

Rappuoli R (2000) Reverse vaccinology. Curr Opin Microbiol 3:445-450

Rappuoli R (2001) Reverse vaccinology, a genome-based approach to vaccine development. In: Vaccine. pp 2688-2691

Rasooli I, Abdolhamidi R, Jahangiri A, Darvish Alipour Astaneh S (2020) Outer membrane protein, Oma87 prevents Acinetobacter baumannii infection. Int J Pept Res Ther. https://doi.org/10.1007/ s10989-020-10056-0

Ren S, Guan L, Dong Y et al (2019) Design and evaluation of a multiepitope assembly peptide vaccine against Acinetobacter baumannii infection in mice. Swiss Med Wkly. https://doi.org/10.4414/ smw.2019.20052

Rizwan M, Naz A, Ahmad J et al (2017) VacSol: A high throughput in silico pipeline to predict potential therapeutic targets in prokaryotic pathogens using subtractive reverse vaccinology. BMC Bioinform 18:106. https://doi.org/10.1186/s12859-017-1540-0

Robbins FC, Robbins JB (1986) Current status and prospects for some improved and new bacterial vaccines*

Rodríguez-Martínez JM, Nordmann P, Ronco E, Poirel L (2010) Extended-spectrum cephalosporinase in Acinetobacter baumannii. Antimicrob Agents Chemother 54:3484-3488. https://doi. org/10.1128/AAC.00050-10

Russo TA, Beanan JM, Olson R et al (2013) The K1 capsular polysaccharide from Acinetobacter baumannii Is a potential therapeutic target via passive immunization. Infect Immun 81:915-922. https://doi.org/10.1128/IAI.01184-12 
Russo TA, Luke NR, Beanan JM et al (2010) The K1 capsular polysaccharide of Acinetobacter baumannii strain 307-0294 is a major virulence factor. Infect Immun 78:3993-4000. https://doi.org/ 10.1128/IAI.00366-10

Samsudin F, Ortiz-Suarez ML, Piggot TJ et al (2016) OmpA: a flexible clamp for bacterial cell wall attachment. Structure 24:22272235. https://doi.org/10.1016/j.str.2016.10.009

Sengupta S, Kumar P, Ciraj AM, Shivananda PG (2001) Acinetobacter baumannii - An emerging nosocomial pathogen in the burns unit Manipal, India. Burns 27:140-144. https://doi.org/10.1016/ S0305-4179(00)00094-2

Sette A, Fikes J (2003) Epitope-based vaccines: an update on epitope identification, vaccine design and delivery. Curr Opin Immunol $15: 461-470$

Sette A, Rappuoli R (2010) Reverse vaccinology: developing vaccines in the era of genomics. Immunity 33:530-541

Shahid F, Zaheer T, Ashraf ST et al (2021) Chimeric vaccine designs against Acinetobacter baumannii using pan genome and reverse vaccinology approaches. Sci Reports 111(11):1-15. https://doi. org/10.1038/s41598-021-92501-8

Shu MH, Matrahim N, Noramdan N et al (2016) An inactivated antibiotic-exposed whole-cell vaccine enhances bactericidal activities against multidrug-resistant Acinetobacter baumannii. Sci Rep 6:1-8. https://doi.org/10.1038/srep22332

Singh R, Singh R, Garg N et al (2014) In silico Analysis of Acinetobacter baumannii Outer Membrane Protein BamA as a Potential Immunogen. Int J Pure Appl Sci Technol 21(2):32-39

Singh R, Capalash N, Sharma P (2016a) Reverse vaccinology: developing vaccine against MDR Acinetobacter baumannii. J Vaccines Vaccin 07:1-3. https://doi.org/10.4172/2157-7560.1000319

Singh R, Garg N, Shukla G et al (2016b) Immunoprotective efficacy of Acinetobacter baumannii outer membrane protein, FilF, predicted in silico as a potential vaccine candidate. Front Microbiol. https://doi.org/10.3389/fmicb.2016.00158

Singh R, Capalash N, Sharma P (2017) Immunoprotective potential of BamA, the outer membrane protein assembly factor, against MDR Acinetobacter baumannii. Sci Rep 7:12411. https://doi.org/ 10.1038/s41598-017-12789-3

Singh JK, Adams FG, Brown MH (2019) Diversity and function of capsular polysaccharide in Acinetobacter baumannii. Front Microbiol 9:3301. https://doi.org/10.3389/fmicb.2018.03301

Solanki V, Tiwari V (2018) Subtractive proteomics to identify novel drug targets and reverse vaccinology for the development of chimeric vaccine against Acinetobacter baumannii. Sci Rep 8:1-19. https://doi.org/10.1038/s41598-018-26689-7

Song X, Zhang H, Zhang D et al (2018) Bioinformatics analysis and epitope screening of a potential vaccine antigen TolB from Acinetobacter baumannii outer membrane protein. Infect Genet Evol 62:73-79. https://doi.org/10.1016/j.meegid.2018.04.019
Srirangaraj S, Segar L, Kali A (2015) Multidrug-resistant Acinetobacter baumannii from nosocomial urinary tract infection: a case report. Asian J Pharm Clin Res 8:6-8

Subhadra B, Oh MH, Choi CH (2019) RND efflux pump systems in acinetobacter, with special emphasis on their role in quorum sensing. J Bacteriol Virol 49:1-11

Tan CH, Li J, Nation RL (2007) Activity of colistin against heteroresistant Acinetobacter baumannii and emergence of resistance in an in vitro pharmacokinetic/pharmacodynamic model. Antimicrob Agents Chemother 51:3413-3415. https://doi.org/10.1128/ AAC.01571-06

Vijayakumar S, Gopi R, Gunasekaran P et al (2016) Molecular characterization of invasive carbapenem-resistant Acinetobacter baumannii from a Tertiary care hospital in South India. Infect Dis Ther 5:379-387. https://doi.org/10.1007/s40121-016-0125-y

Vivona S, Bernante F, Filippini F (2006) NERVE: new enhanced reverse vaccinology environment. BMC Biotechnol 6:35. https:// doi.org/10.1186/1472-6750-6-35

Vivona S, Gardy JL, Ramachandran S et al (2008) Computer-aided biotechnology: from immuno-informatics to reverse vaccinology. Trends Biotechnol 26:190-200

Wang X, Cole CG, DuPai CD, Davies BW (2020) Protein aggregation is associated with Acinetobacter baumannii desiccation tolerance. Microorganisms 8:343. https://doi.org/10.3390/microorgan isms 8030343

Wang-Lin SX, Olson R, Beanan JM et al (2017) The capsular polysaccharide of Acinetobacter baumannii is an obstacle for therapeutic passive immunization strategies. Infect Immun. https://doi.org/ 10.1128/IAI.00591-17

Xu C, Bilya SR, Xu W (2019) adeABC efflux gene in Acinetobacter baumannii.New Microbes New Infect 30

Yang FL, Li XS, Liang XW et al (2012) Detection of virulence-associated genes in Staphylococcus aureus isolated from bovine clinical mastitis milk samples in Guangxi. Trop Anim Health Prod 44:1821-1826. https://doi.org/10.1007/s11250-012-0143-z

Yang FL, Lou TC, Kuo SC et al (2017) A medically relevant capsular polysaccharide in Acinetobacter baumannii is a potential vaccine candidate. Vaccine 35:1440-1447. https://doi.org/10.1016/j.vacci ne.2017.01.060

Zadeh Hosseingholi E, Rasooli I, Mousavi Gargari SL (2014) In silico analysis of Acinetobacter baumannii phospholipase D as a subunit vaccine candidate. Acta Biotheor 62:455-478. https://doi.org/ 10.1007/s10441-014-9226-8

Zimbler DL, Penwell WF, Gaddy JA, et al (2009) Iron acquisition functions expressed by the human pathogen Acinetobacter baumannii. In: BioMetals. Springer, pp 23-32 